J. Lake Sci. (湖泊科学), 2015, 27(1): 190-194

http: //www. jlakes.org. E-mail : jlakes@niglas.ac.cn

(C) 2015 by Journal of Lake Sciences

\title{
松辽盆地嫩江组下部水体分层的有机地球化学证据”
}

\author{
刘美羽 ${ }^{1,2}$,胡建芳 ${ }^{1 * *}$, 万晓樵 ${ }^{2}$ \\ (1: 中国科学院广州地球化学研究所,广州 510640) \\ (2:中国地质大学(北京) 地球科学与资源学院,北京 100083 )
}

\begin{abstract}
摘 要: 通过对松科 1 井样品的测试分析, 在松辽盆地姚家组二、三段顶部至嫩江组二段底部地层中检测到了较高含量的伽 马蜡烷, 并据此确认了对应时期水体分层事件的存在. 通过其与总有机碳 (TOC) 值和 $\delta^{13} \mathrm{C}_{\mathrm{org}}$ 值剖面变化趋势比对发现, 伽马 蜡烷含量的高值与 TOC 高值和 $\delta^{13} \mathrm{C}_{\mathrm{org}}$ 负值对应良好, 表明水体分层在一定程度上促进了嫩江组沉积时期缺氧事件的发生, 进而对有机质的保存起到了积极的作用. 这种水体分层与当时的海侵事件密切相关.
\end{abstract}

关键词: 松辽盆地; 伽马蜡烷;水体分层;嫩江组;总有机碳

\section{The organic geochemical evidences for the lake water stratification in Lower Nenjiang For- mation, Songliao Basin}

\author{
LIU Meiyu ${ }^{1,2}$, HU Jianfang ${ }^{1} \&$ WAN Xiaoqiao ${ }^{2}$ \\ (1: Guangzhou Institute of Geochemistry, Chinese Academy of Sciences, Guangzhou 510640, P. R. China) \\ (2: School of Earth Sciences and Resources, China University of Geosciences, Beijing 100083, P. R. China)
}

\begin{abstract}
By the analysis of samples from SK-1, high content gammacerane was detected in the strata from the top of the $2^{\text {nd }}$ and $3^{\text {rd }}$ member of Yaojia formation to the bottom of the $2^{\text {nd }}$ member of Nenjiang Formation, Songliao Basin, which suggesting that water stratification occurred during this period. Compared with the total organic carbon(TOC) and $\delta^{13} \mathrm{C}_{\mathrm{org}}$ data, the high contents of gammacerane correspond well with the high values of TOC and the negative values of $\delta^{13} \mathrm{C}_{\mathrm{org}}$. This correspondence suggests that water stratification led to the anoxic environment in the Songliao Paleo-lake, which contributed to the preservation and deposit of organic matter during the sedimentary period of Nenjiang Formation. It is inferred that the water stratification is related to the marine incursion in the Songliao Basin.
\end{abstract}

Keywords: Songliao Basin; gammacerane; water stratification; Nenjiang Formation; total organic carbon

地质历史时期曾经出现过多次全球性的缺氧事件, 并且由于有些缺氧事件发生的区域较广, 形成了在全 球范围内广泛发育的黑色页岩层,使其成为地层对比的重要标志之一. 由于水体缺氧,有机质的喜氧生物降解 骤减,有利于富氢、倾油有机质的保存,为形成大规模优质烃源岩提供了物质基础 ${ }^{[1]}$.

大量的研究表明: 对于陆相沉积环境来说, 不论是古代还是现代湖泊, 其底部水体或沉积物中的缺氧都与 水体的垂向分层密切相关 ${ }^{[2-4]}$, 甚至在某些情沉下,水体的微弱分层即可导致显著的水柱化学性质的垂向变 化 ${ }^{[3]}$. 这是由于一般的水体分层界面(化跃面)的存在,会导致界面上下水体的交换受阻,在界面上下形成具有 较大性质差异的水体环境 ${ }^{[2-3]}$. 化跃面上部为混合良好的富氧循环水体, 化跃面下部则为不流通的微氧或缺氧 水体,其下覆沉积环境具有还原特征 ${ }^{[5-8]}$, 此种由分层所带来的水体中氧化/还原条件的变化对沉积有机质的 保存具有重要影响 ${ }^{[9]}$. 水体分层包括温度分层和盐度分层, 温度分层多出现在赤道附近的大型湖泊, 盐度分层 在海洋和湖泊中都存在 ${ }^{[10]}$.

关于松辽盆地白严纪优质烃源岩形成发育的沉积环境的研究已经取得了一定的进展, 研究表明富有机质

* 国家重点基础研究发展计划“973”项目 (2012CB822002) 和国家自然科学基金项目 (41372110) 联合资助. 2013 - 12 09 收稿;2014-05-12 收修改稿. 刘美羽(1987 ), 女,硕士;E-mail :ninina@ qq. com.

** 通信作者;E-mail:hujf@ gig. ac. cn. 
烃源岩形成于湖泊缺氧时期,且当时的水体环境为淡水至微咸水 ${ }^{[11-12]}$, 但关于松辽盆地白严纪水体分层的系 统研究还少见报导. 本文将以有机地球化学手段来研究松辽盆地嫩江组的水体分层状况,为探讨其优质烃源 岩的形成机制提供基础资料.

\section{1 松辽盆地和松科 1 井}

松辽盆地是世界范围内陆相白严纪地层和地质记录最完整的地区之一 ${ }^{[13]}$, 位于中国东北部, 横跨黑龙江、 吉林、辽宁和内蒙古 4 省区, 长约 $820 \mathrm{~km}$, 宽约 $350 \mathrm{~km}^{[14]}$, 面积达 $260000 \mathrm{~km}^{2}$, 为中生代形成的伸展断陷盆地 (图 1). 盆地内地层覆盖非常严重,仅在局部地区才有少量白严系出露,所以盆地地层层序的建立主要依赖于 位于盆地内的数万口钻井所取得的数十万米岩心资料 ${ }^{[15]}$. 盆地内部的白严系可以分为 10 个组,自下而上依次 为下白严统的火石岭组、沙河子组、营城组、登娄库组、泉头组和上白严统的青山口组、姚家组、嫩江组、四方台 组、明水组.

松科 1 井是全球在陆地上实施的第一口陆相白严纪科学钻井, 采用了“一井双孔” 的施工方案, 由南孔和 北孔组成 (图 1). 其中取心层位为南孔嫩江组二段底部到泉头组三段顶部, 北孔泰康组到嫩江组一段顶部, 并 利用在全盆地可对比的濑江组底部的油页岩层将两孔衔接起来 ${ }^{[13]}$. 松科 1 井的实施,使中国东北地区的晚白 严世陆相地层得以连贯起来,为地层划分、对比及格架的建立提供了丰富可靠的资料.

前人的研究已经证明在嫩江组一二段沉积时期,松辽盆地发生了盆地演化史上规模最大的海侵事件,并 引发了全盆地缺氧事件 ${ }^{[16]}$, 沉积了一套可以作为优质烃原岩的含多层油页岩的黑色页岩层 ${ }^{[17]}$. 此次缺氧事件 的发生是否是由于水体的分层而导致的, 目前还没有进行系统的研究; 此外,如果水体存在分层,其分层程度 如何, 本文通过对特定生物标志化合物的定量计算将有助于回答此问题.

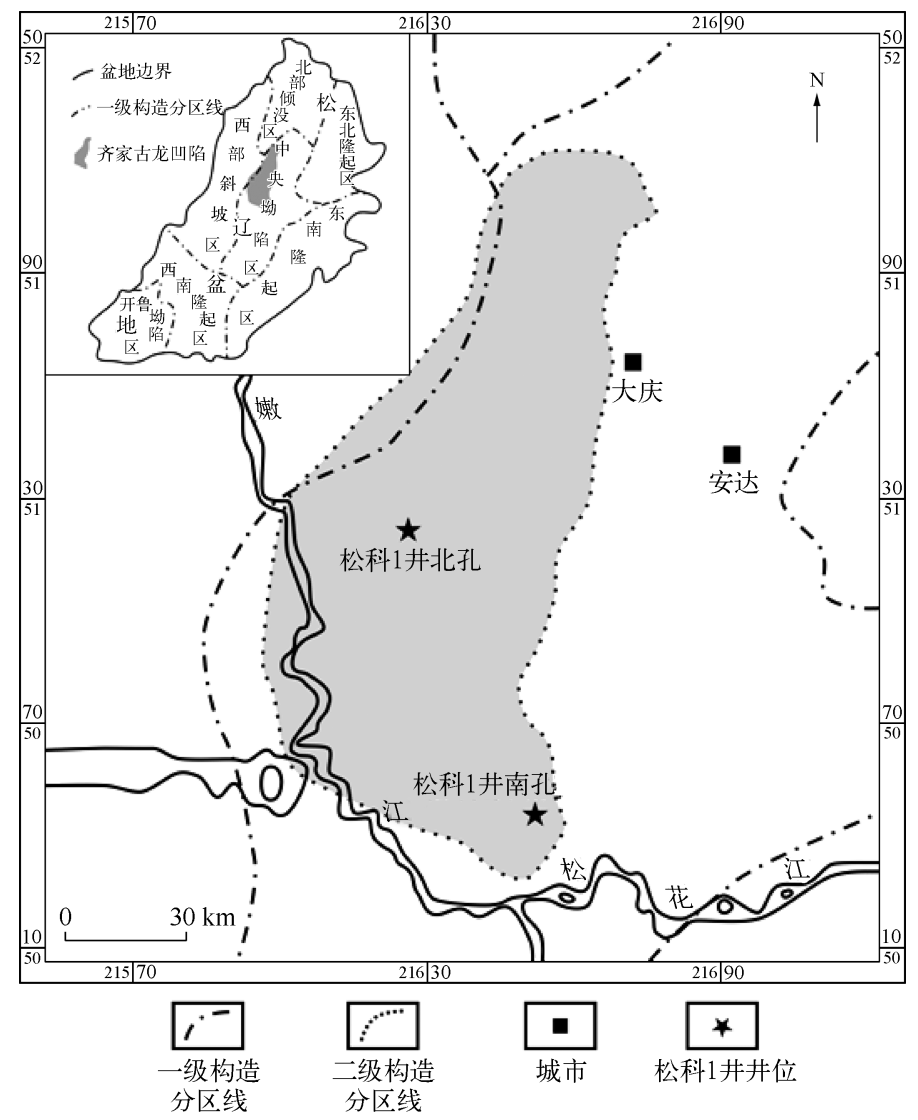

图 1 松科 1 井井位图 ${ }^{[30]}$

Fig. 1 Sketch map showing the location of the SK-1 Cores 


\section{2 样品采集及分析}

为了探究松辽盆地嫩江组一、段沉积时期的水体分层事件存在性及其与当时的缺氧事件之间的联系, 本研究选取了松科 1 井两孔的岩心样品中姚家组二、三段上部至嫩江组三段底部的共计 61 个样品. 具体包括 姚家组二、三段 6 个, 取样间隔 $4 \sim 17 \mathrm{~m}$ 不等, 下疏上密; 嫩江组一段 26 个, 取样间隔大多为 $3 \mathrm{~m}$ 左右, 个别较 密的部分为 $1 \sim 2 \mathrm{~m}$, 较为稀疏的部分为 $6 \sim 7 \mathrm{~m}$; 嫩江组二段 27 个, 取样间隔 $4 \sim 12 \mathrm{~m}$, 下部较上部稍密; 嫩江组 三段 2 个,取样间隔为 $20 \mathrm{~m}$ 左右.

岩心样品均粉碎至 100 目后分成两部分进行前处理.

元素分析和 $\delta^{13} \mathrm{C}_{\text {org }}$ 值分析: 称取 $100 \mathrm{mg}$ 左右样品加人过量稀盐酸静置过夜, 反应完全后用去离子水清洗 多次至中性, 后在 $60{ }^{\circ} \mathrm{C}$ 烘干至恒重. 分别称取适量样品于 Vario EL CUBE 元素分析仪和 DELTA ${ }^{\text {plus }} \mathrm{XL}$ 同位素 质谱仪进行 $\mathrm{C}$ 元素分析和 $\delta^{13} \mathrm{C}_{\text {org }}$ 分析元素分析, 数据结果表达为 $\mathrm{TOC}(\mathrm{wt} \%)$. 每个样品均测定平行双样. 最终 结果为其平均值. 对某一样品重复测试 (5 次), 其标准偏差 $\sigma$ 为: $\pm 0.02 \mathrm{wt} \% \mathrm{C}, \delta^{13} \mathrm{C}_{\mathrm{org}}$ 分析误差 $< \pm 0.5 \%$.

生物标志化合物分析: 称取 $20 \sim 30 \mathrm{~g}$ 粉碎均匀的样品, 加人适量 $n \mathrm{C}_{24} \mathrm{D}_{50}$ 标准化合物为内标, 用二氯甲烷 索氏抽提 $48 \mathrm{~h}$, 经氧化铝-硅胶色谱柱进行逐组分分离, 由正己烷淋洗得到烷烃组分, 于 Thermo TRACE GC ULTRA/DSQII 气相色谱一质谱仪进行伽马蜡烷的检测分析, 仪器条件如下: 使用全扫描 (Full Scan) 和选择离子扫 描(SIM) 模式, SIM 模式选择接收 $\mathrm{m} / \mathrm{z}=191$ 的离子; 离子源温度 $230{ }^{\circ} \mathrm{C}$, 进样口 $300{ }^{\circ} \mathrm{C}$, 无分流; 色谱条件为 80 ${ }^{\circ} \mathrm{C}$ 保持 $2 \mathrm{~min}, 15^{\circ} \mathrm{C} / \mathrm{min}$ 的升温速率升至 $120^{\circ} \mathrm{C}$, 再以 $3^{\circ} \mathrm{C} / \mathrm{min}$ 升至 $300{ }^{\circ} \mathrm{C}$ 保持 $30 \mathrm{~min}$.

\section{3 结果}

嫩江组一二段 TOC 为 $0.3 \% \sim 4.7 \%$. 嫩江组一段 TOC 呈现出波动式增高. TOC 高值主要集中在嫩江组一 段的 $1038 \sim 1045 、 1050 \sim 1065 、 1068 \sim 1072 、 1075 \sim 1100 、 1118 \sim 1130$ 和 $1150 \sim 1170 \mathrm{~m}$ 深度处, 其下覆地层姚家 组 TOC 普遍低于 $0.3 \%$. 剖面 $\delta^{13} \mathrm{C}_{\mathrm{org}}$ 值变化范围为: $-24.2 \% o \sim-30.4 \%, \delta^{13} \mathrm{C}_{\mathrm{org}}$ 值在嫩江组一段发生明显偏 负, 最负为 $-30.4 \%$, 嫩江组二段开始逐渐偏正, 到嫩江组三段已达 $-24.2 \%$; 在嫩江组一段, 与 TOC 高值对 应, 具体表现在 $1038 \sim 1045 、 1050 \sim 1065 、 1068 \sim 1072 、 1075 \sim 1100$ 和 $1118 \sim 1130 \mathrm{~m}$ 深度处 $\delta^{13} \mathrm{C}_{\mathrm{org}}$ 值都显著偏 负. 在姚家组二三段中部、嫩江组二段中上部、嫩江组三段底部区间内, $\delta^{13} \mathrm{C}_{\mathrm{org}}$ 值在较为偏正的 $-27 \%$ $-24 \%$ 。 之间缓慢地变动.

伽马蜡烷主要于嫩江组一二段被检测出来, 其含量范围为 $0.24 \sim 581.83 \mathrm{ng} / \mathrm{g}$, 最高值出现在嫩一段中 部. 在嫩江组一段、二段底部, 伽马蜡烷表现出同 TOC 一致的变化趋势, 其高值也主要出现在 $1030 \sim 1040$ 、 $1038 \sim 1045 、 1050 \sim 1065 、 1068 \sim 1072 、 1075 \sim 1100$ 和 $1118 \sim 1130 \mathrm{~m}$ 深度处. 在姚家组二三段中部、嫩江组二段 中上部、嫩江组三段底部区间内,伽马蜡烷几乎检测不出.

\section{4 讨论}

伽马蜡烷是一种来源于四膜虫醇的 $\mathrm{C}_{30}$ 带环烷烃, 最初的研究认为伽马蜡烷是高盐环境的生物标志化合 物 ${ }^{[18-23]}$, 但随后伽马蜡烷的重碳同位素及微生物学均表明生活于化跃面、循环水体与非循环水体的界面及其 底部厌氧环境中的纤毛虫是伽马蜡烷的重要来源, 由于纤毛虫生活于分层的水体中, 故伽马蜡的存在和较高 丰度还可以作为水体分层的标志 ${ }^{[2-25]}$. 本研究中, 嫩江组一段、二段底部伽马蜡烷的检出表明松辽古湖泊在这 一时段存在水体分层现象.

前人对于松辽盆地烃源岩形成发育时期的沉积环境特征的研究表明其富有机质烃源岩形成时期松辽古 湖泊为淡水至微咸水沉积环境 ${ }^{[11]}$. 嫩江组古盐度定量重建也表明当时湖泊下部的水体盐度为 $30 \%$ 40\%o, 上 部为 $1 \%$ 30\%o, 即此时湖泊水柱盐度不均一, 存在盐度分层 ${ }^{[26]}$. 伽马蜡烷的检出再次证明了此时水体分层现 象. 由于松辽古湖泊在其历史演化过程中一直是大型淡水湖泊, 越来越多的研究表明, 松辽盆地在嫩江组一、 二段沉积时期发生了大规模的海侵事件, 相关证据 (咸水一半咸水动物群 ${ }^{[14]}$ 、钙质超微化石 ${ }^{[27]} 、 \mathrm{C}_{31}$ 甾烷 ${ }^{[28]} 、$ 有 孔虫 ${ }^{[29-30]}$ 等) 也不断提出, 但海侵发生的模式以及相对规模目前还没有进行系统研究. 本研究通过对水体分层 标志物——伽马蜡烷的定量研究, 能够指示水体分层的相对规模 (程度), 也间接指示了海侵的规模. 从图 2 看 
出, 嫩江组一段、二段底部伽马蜡烷的相对峰值是波动式的, 反映出湖泊水体分层是波动/间歇式的, 规模也有 大有小,推测此时海侵的发生是由于海、湖平面都较高 ${ }^{[31]}$, 海平面的微小升高, 海水就能以片泛的形式进人. 松 辽古湖泊海水的进人,一方面给湖泊带来了大量的海洋初级生产力, 另一方面给湖泊带来了丰富的营养盐, 促 进了湖泊自身初级生产力的大幅增加. 上部低盐度水体中大量菌藻类的暴发产生的有机质残屑沉降至下部高 盐度水体中, 分层水体使得水体缺氧,形成还原环境, 有利于大量有机质的保存埋藏 ${ }^{[1]}$, 最终形成富有机质烃 源岩. 因此, 此时地层中对应 TOC 的含量增高. $\delta^{13} \mathrm{C}_{\mathrm{org}}$ 值显示在水体分层时, 其值整体偏负 (可达 $-30.4 \%$ ), 反 映出湖泊沉积有机质中有海洋有机质的贡献, 这是因为研究表明, 白严纪或更老沉积物中海洋来源有机质的 $\delta^{13} \mathrm{C}_{\mathrm{org}}$ 值比湖泊来源有机质偏轻,一般可以将 $\delta^{13} \mathrm{C}_{\mathrm{org}}$ 值为 $-29 \%$ - 27\%o的有机质划分为海洋来源, 而将 $\delta^{13} \mathrm{C}_{\mathrm{org}}$ 值为 $-25 \% 0 \sim-24 \%$ 的有机质划分为陆相湖泊来源 ${ }^{[32]}$. 嫩二段开始, $\delta^{13} \mathrm{C}_{\mathrm{org}}$ 值缓慢偏正, 表明海洋有机质 的输人消失, 海侵结束, 松辽古湖泊水体分层现象也基本消失.

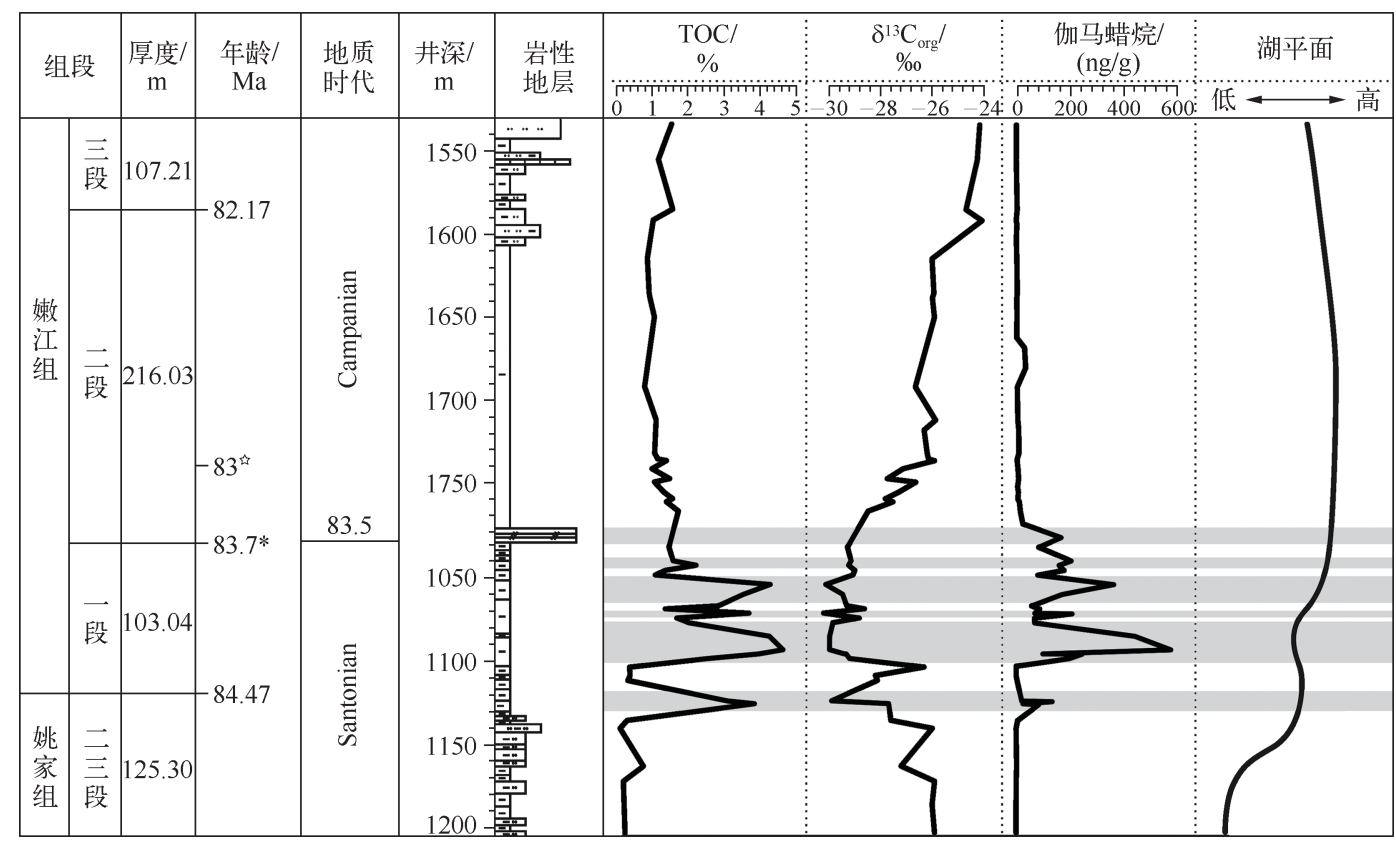

图 2 松辽盆地白严纪中期姚家组顶部一嫩江组下部沉积剖面沉积物总有机碳及其稳定碳同位素、伽马蜡 烷及湖平面变化趋势 (代表古地磁年龄, * 为实测 SIMS 锆石 U-Pb 年龄; 岩性柱条中虚线代表泥 岩,点代表砂岩, 斜双线代表油页岩)

Fig. 2 TOC, stable carbon isotopic composition of TOC, content of gammacerane and lake level change in mid-Cretaceous Stratigraphic column of Songliao Basin

\section{5 结论}

松科 1 井嫩江组下部的伽马蜡烷定量研究表明,松辽古湖泊此时存在水体分层现象,这种分层是由于海 侵的发生使得湖泊水体上、下部存在显著的盐度差异. 水体的分层有利于形成湖泊水柱下部的还原环境,有利 于有机质的保存埋藏,并最终形成富有机质的烃源岩. 伽马蜡烷的相对峰值表明嫩江组一段、二段底部水体分 层是间歇/波动式的,间接反映此时海侵是间歇式发生的.

\section{6 参考文献}

[ 1 ] 侯读杰, 冯子辉, 黄清华. 松辽盆.地白严纪缺氧地质事件的地质地球化学特征. 现代地质,2003,17(3):311-317.

[2] 王敬富,陈敬安,杨永琼等. 红枫湖季节性热分层消亡期水体的理化特征. 环境科学研究,2012,25(8):845-851. 
[3] 夏品华, 林 陶, 李存雄等. 贵州高原红枫湖水库季节性分层的水环境质量响应. 中国环境科学, 2011,31 (9): 1477-1485.

[4] 张 靖, 刘小龙, 高 洋等. 百花水库水质模拟及季节性水质恶化控制对策. 上海大学学报: 自然科学版, 2013,19(5): 441-447.

[ 5 ] Mellard JP, Yoshiyama K, Litchman E et al. The vertical distribution of phytoplankton in stratified water columns. Journal of Theoretical Biology, 2011,269 (1):16-30.

[6] Wetzel RG. Limnology. W. B. Saunders Company, 1975.

[ 7 ] Wuest A, Piepke G, van Senden DC. Turbulent kinetic energy balance as a tool for estimating vertical diffusivity in windforced stratified waters. Limnology and Oceanography, 2000,45(6) :1388-1400.

[ 8 ] Nakamura Y, Hayakawa N. Modelling of thermal stratification in lakes and coastal seas. Hydrology of Natural and Ntanmade Lakes , $1991,206: 227-236$.

[9] 张枝焕,杨 藩,李东明等. 中国新生界咸化湖相有机地球化学研究进展. 地球科学进展,2000,15(1):65-69.

[10] K. E. 彼得斯, C. C. 沃尔特斯,J. M. 莫尔多万著. 张水昌, 李振西等译. 生物标志化合物指南: 第 2 版. 北京: 石油工业出 版社, 1997:8-11.

[11] 冯子辉,方 伟, 李振广等. 松辽盆地陆相大规模优质烃源岩沉积环境的地球化学标志. 中国科学: 地球科学, 2011, $\mathbf{4 1}$ (9) :1253-1267.

[12] 王东坡,刘 立,张立平等. 松辽盆地白严纪古气候沉积旋回层序地层. 长春: 吉林大学出版社,1995.

[13] 高有峰,王成善,王璞珺. 松科 1 井北孔选址,岩心剖面特征与特殊岩性层的分布. 地学前缘,2009,16(6):104-112.

［14］刘招君,王东坡,刘 立等. 松辽盆地白严纪沉积特征. 地质学报,1992,66(4):327-338.

[15］黄清华. 松辽盆地晚白严世地层及微体古生物群 [学位论文]. 北京:中国地质科学院地质研究所,2007.

[16］黄清华,陈春瑞. 松辽盆地晚白严世生物演化与古湖泊缺氧事件.微体古生物学报,1998,15(4):417-425.

[17] Feng ZH, Fang W, Wang X et al. Microfossils and molecular records in oil shales of the Songliao Basin and implications for paleo-depositional environment. Science in China Series D:Earth Sciences, 2009,52(10):1559-1571.

[18] Peters KE, Moldowan JM. The biomarker guide: interpreting molecular fossils in petroleum and ancient sediments. Englewood Cliffs, NJ: Prentice Hall, 1993.

[19］包建平,朱翠山,汪立群. 柴达木盆地西部原油地球化学特征对比. 石油与天然气地质,2010,31(3):353.

[20] 胡 瑛, 张枝焕, 李 伟等. 黄骅坳陷滩海三马地区烃源岩分子标志物特征及其沉积相指示意义. 沉积学报, 2006,24 (3) :419-425.

[21] Wang G, Wang TG, Simoneit BRT et al. The distribution of molecular fossils derived from dinoflagellates in Paleogene lacustrine sediments (Bohai Bay Basin, China). Organic Geochemistry, 2008,39(11):1512-1521.

[22] 杨 群. 分子古生物学原理与方法. 北京:科学出版社,2003:96-139.

[23] 傅家漠,盛国英. 分子有机地球化学与古气候,古环境研究. 第四纪研究, 1992,4:306-320.

[24] SinningheDamsté JS, Kenig F, Koopmans MP et al. Evidence for gammacerane as an indicator of water column stratification. Geochimicaet Cosmochimica Acta, $1995, \mathbf{5 9}(9)$ :1895-1900.

[25] 张立平,黄弟藩. 伽马蜡烷一一水体分层的地球化学标志. 沉积学报,1999,17 (1):136-140.

[26] Wang L, Song Z, Yin Q et al. Paleosalinity significance of occurrence and distribution of methyl trimethyltridecyl chromans in the Upper Cretaceous Nenjiang Formation, Songliao Basin, China. Organic Geochemistry, 2011,42(11):1411-1419.

[27]叶淑芬,魏鬼生. 松辽盆地白严系的密集段及海水进侵的新证. 地球科学: 中国地质大学学报, 1996,21(3):267-271.

[28］侯读杰,王铁冠. 松辽盆地原油和沉积物中 $\mathrm{C}_{31}$ 甾烷的发现与意义. 科学通报, 1998,43(23):2550-2553.

[29］涂玉洁. 松辽盆地白严纪有孔虫化石与海侵证据. 北京:中国地质大学,2012.

[30 ] Xi DP, Wan XQ, Feng ZQ et al. Discovery of Late Cretaceous foraminifera in the Songliao Basin: evidence from SK-1 and implications for identifying seawater incursions. Chinese Science Bulletin, 2011 ,56(3):253-256.

[31] Haq BU, Hardenbol J, Vail P. Chronology of fluctuating sea levels since the Triassic. Science, 1987,235:1156-1167.

[32] Arthur MA, 黄泽辉. 现代海洋有机碳中 ${ }^{13} \mathrm{C}$ 的异常富集. 海洋石油,1986,3:009. 